\title{
Gabriella Hild*
}

Department of Languages for Biomedical Purposes and Communication University of Pécs Medical School, Hungary

gabriella.hild@aok.pte.hu

\section{Timea Németh}

Department of Languages for Biomedical Purposes and Communication University of Pécs Medical School, Hungary

timea.nemeth@aok.pte.hu

\section{Alexandra Csongor}

Department of Languages for Biomedical Purposes and Communication University of Pécs Medical School, Hungary

alexandra.csongor@aok.pte.hu

\section{THE IMPACT OF USING INTERNATIONAL MEDICAL STUDENTS IN ROLE-PLAYS ON IMPROVING HUNGARIAN MEDICAL STUDENTS' ENGLISH LANGUAGE COMPETENCE}

\section{Abstract}

The present study aimed to elicit the views and perceptions of Hungarian medical students on the use of peer tutors in doctor-patient role-play activities in English for Medical Purposes (EMP) classes. The peer tutors were either native speakers of English or had a good command of English and enrolled in the English medium programme of the same university. We wanted to tackle the problem of the unwillingness of Hungarian students to communicate in English in their EMP classes and provide a more motivating and natural language learning environment in which the target language was the lingua franca. In addition, we aimed to improve the participants' intercultural competence by providing a platform where the local and the international students could meet, work together and socialise. At the end of the courses, the Hungarian students were interviewed and asked for feedback on these activities. The data was thematically analysed and the results showed that the Hungarian medical students were enthusiastic and motivated to participate and interact in English during the role-plays. The interview findings also demonstrated that the role-play activities succeeded in bringing the Hungarian and foreign students closer and weakening or even removing the invisible cultural wall between them.

\section{Key words}

international undergraduate teaching assistants, English for Medical Purposes, foreign language oral skills, intercultural competence, role-plays, peer tutoring.

\footnotetext{
* Corresponding address: Gabriella Hild, UP Medical School, Department of Languages for Biomedical Purposes, Szigeti út 12, 7624 Pécs, Hungary.
} 


\section{INTRODUCTION}

The present paper summarises the findings of a qualitative, exploratory study which aimed to elicit Hungarian medical students' views and perceptions on utilising peer tutors in doctor-patient role-play activities in English for Medical Purposes (EMP) classes. We invited international students of the English-medium programme of the University of Pécs Medical School (UPMS), Hungary to act as peer tutors as we wanted to increase Hungarian medical students' willingness to communicate in the target language in class and, consequently, improve their oral language skills. The aim was to provide a natural language learning environment in which the target language was the lingua franca. In addition, we wanted to create a new platform for the local and the foreign students of the university to share experience and socialise, and, in doing so, perhaps remove the invisible cultural wall, which we believed existed between them.

A peer tutor has been defined as "anyone who is of a similar status as the person being tutored and operates as a complement and active partner with university teachers in the process of learning and teaching" (Stigmar, 2016: 124). In general, peer tutors are older, or more capable (i.e. academically successful) than their tutees. Their main task is to facilitate the learning process and not to teach or introduce new material. Several terms, such as peer tutoring, peer supported learning, collaborative learning, or peer-assisted learning (Olaussen, Reddy, Irvine, \& Williams, 2016) have been used in the literature. Peer Assisted Learning (PAL) is the umbrella term and refers to a method in which students learn from students (Topping \& Ehly, 1998). By involving students in the learning and teaching process, PAL can improve motivation and class performance, and increase development of collaboration and communication skills. It has benefits for all participants including the peer tutors, the students and the teachers (Dandavino, Snell, \& Wiseman, 2007). The idea of peer tutoring is also underpinned by Vygotsky's idea of learning (1987), according to which learning can take place when a more knowledgeable person is present.

Studies have shown that in higher education PAL models can increase motivation and give incentive to students to put more effort into studying (Cate \& Durning, 2007). Peer tutors may also serve as role models for younger students and help reduce anxiety in the classroom (Lockspeiser, 2006). PAL can be beneficial in any classroom including foreign language classes. The positive outcome of peer tutoring in enhancing English language learners' performance is well documented (Bowman-Perrott, deMarín, Lakshmi, \& Etchells, 2016; Cole, $2013,2014)$. However, the context of the majority of these studies is primary or secondary school education. In one of the studies that investigated English as a Foreign Language peer tutoring in higher education, tutees at a university in the United Arab Emirates reported that their English skills and confidence had improved and they felt less intimidated while using English with their peer tutors (Mynard \& Almarzouqi, 2006). 
In terms of the use of PAL in the EMP classroom, the literature is scarce. We only found one conference presentation, which outlined a study on the use of peer tutors to teach Medical English vocabulary at a Turkish medical university. Feedback from the participants was obtained in the form of a survey including open- and closed-end questions. More than half of the tutees believed that PAL "was an enjoyable process" and more effective and beneficial for preparing for the Medical English exams than studying on their own. Around 50\% reported that PAL reduced their anxiety during the Medical English course.

In a multicultural student population, such as the one at UPMS, which runs a medical degree programme in three languages (Hungarian, English and German), peer tutors used in foreign language classes can be native or near-native speakers of the target language and, thus, can create a more natural and motivating language learning environment. While providing an opportunity to improve speaking skills with the help of fellow students, these classes can simultaneously facilitate students' intercultural competence, which is also imperative for healthcare professionals in our globalised world (Kleinman \& Benson, 2006; Marek et al., 2019; McWhinney, 1989; Németh \& Tseligka, 2018; Schouten \& Meeuwese, 2006). One of the most cited definitions describes intercultural competence as "a complex of abilities needed to perform effectively and appropriately when interacting with others who are linguistically and culturally different from oneself" (Fantini, 2006: 12). Nowadays, there are few countries where the patient population can be described as truly monocultural. Research findings have long demonstrated that improved intercultural competence is essential for healthcare professionals to enable them to provide better care within multicultural settings (Cohen, Chavez, \& Chehimi, 2010; Goode, Haywood, Wells, \& Rhee, 2009; Hamilton, 2009; Lie, Lee-Rey, Gomez, Bereknyei, \& Braddock, 2011; Saha \& Fernandez, 2007; Stütz, Green, McAllister, \& Eley, 2015). Since, similarly to many other medical schools (Crandall, George, Marion, \& Davis, 2003), at our university the development of intercultural competence is not yet part of the core medical curriculum, our department decided to integrate it into certain Medical English and German courses. Inviting international medical students into EMP classes to act as peer tutors is part of this initiative.

Role-play is a commonly used teaching technique within the approach of communicative language teaching. Kuśnierek (2015: 7) defined role-play as a "complete range of communication technique which develops language fluency and promotes student interaction during the class, increasing students' motivation, encouraging their learning, but also sharing responsibilities between teacherstudent". It requires students to collaborate to create meaning in real-life scenarios. Instead of passively listening students have to negotiate for meaning and develop strategies for communication breakdowns (Kuśnierek, 2015). By letting students experience and solve the difficulties of real-world communication within the safety net of the classroom, teachers can better prepare them to be effective communicators in the target language. Research has demonstrated that role-play 
can increase learners' intercultural awareness and motivation (Sato, 2001; Shapiro \& Leopold, 2012), and improve oral fluency (Al-Senaidi, 2009). Role-plays can be specifically adapted to students' real-life language needs and, therefore, improve students' classroom performance. Since in these tasks vocabulary specific to the given scenario or social context is used, role-plays are extensively applied in teaching languages for specific purposes, such as EMP (Dorathy \& Mahalakshmi, 2011). Over the past three decades it has also become increasingly apparent that doctors' communicative competence with their patients or colleagues has a considerable bearing on establishing the correct diagnosis and facilitating patient compliance with treatment (Betancourt \& Green, 2010; Daetwyler, Cohen, Gracely, \& Novack, 2010; Lie et al., 2011). To provide medical students with authentic contexts where they can acquire the necessary skills, role-plays and low and high fidelity simulation are common in medical education (Franklin-Landi, 2017; Hoekje, 2012; Nestel \& Tierney, 2007; Pavel, 2014). By using role-plays in the EMP classroom, language teachers can create situations specifically tailored to the needs of medical students, and, hence, integrate foreign language learning into their medical studies. During these role-plays, medical students can combine their knowledge of medicine with their EMP knowledge, which can increase learner engagement (Staley, Allen, \& Hamp, 2020). Role-play activities contain meaningful tasks to accomplish, motivating students further to use the target language. While the use of role play in English as a Foreign Language (EFL) and English as a Second Language (ESL) context is well researched (e.g. Duxbury \& Ling, 2010; Gass \& Mackey, 2006; Zhang, 2010), to the best of our knowledge, no research has been conducted into its use in the EMP classroom. However, it may have been covered partly by the existing ESL and EFL literature. Our investigation approached this topic from the students' perspective and aimed to shed light on what their views and impressions were while role-playing medical scenarios with international peer tutors in EMP classes. The experimental aspect of our investigation lies in the fact that these peer tutors, hereafter called international medical undergraduate teaching assistants (IMUTAs), were medical students attending the same university but coming from countries all over the world. As such, they created an educational environment that was different from the one the Hungarian students were used to. At our university EMP classes are currently offered only to Hungarian students. In other words, while role-playing and working in groups or pairs, which are all typical of our foreign language classes, Hungarian students interact with other Hungarian students. While role-playing with the IMUTAs, the Hungarian students were faced with challenges related to cultural differences and the fact that they did not share the same first language.

In the next section we describe the research context, which is followed by a description of the participants in the study and details regarding the role-play activities that were carried out. The research methodology and data collection methods are presented. This is followed by the results, and a discussion of these 
results. Finally, we present our conclusions and make some suggestions for followup studies.

\section{THE CONTEXT}

The present study was conducted at the Department of Languages for Biomedical Purposes and Communication of UPMS during the spring semester of the academic year 2018/2019. The Department runs various EMP courses for the Hungarian, and Medical Hungarian courses for the international students. The UPMS offers Hungarian as well as English- and German-medium programmes. The students of the English programme come from all over the world (e.g. Japan, South Korea, Norway, China, Iran, Jordan, UK, USA, etc.). The majority of the students of the German programme are from Germany or Austria. The number of international students has increased dramatically at UPMS over the last few years. In the academic year 2018/2019, more than half of the students admitted to our university were international. Although the students of these three programmes attend the same university, it can be considered common knowledge that they do not socialise among themselves and tend to interact mainly with their own compatriots (Hild, Csongor, \& Németh, in press).

In order to take advantage of the benefits of this multicultural environment, the Department of Languages for Biomedical Purposes started an undergraduate teaching assistant programme five years ago. Within the framework of this initiative, we recruited peer tutors, called IMUTAs, from the medical students attending the English-medium programme. In addition to teaching Medical English to the Hungarian students, our department teach Medical Hungarian to these international students in the first two years of their university studies. The international students need a knowledge of Medical Hungarian in order to be able to communicate with Hungarian patients during their clinical rotation courses starting from year 3. During these Medical Hungarian courses, where the language of instruction is English, we usually approach international students who are either native speakers or demonstrate an excellent command of the English language and are sociable enough to act as peer tutors. As IMUTAs they assist foreign language teachers during Medical English classes where the focus is on oral skills. They are required to attend a particular number of EMP classes and act as peer tutors during pair- and teamwork, design classroom games or assist the teacher whom they are assigned to in the preparation for the classes. In return for their assistance, they are given elective credits at the end of each semester in which they signed up for this programme.

In the present study, one of the main reasons for us to use the assistance of IMUTAs was to tackle the problem of our Hungarian students' unwillingness to communicate in English in class. Foreign languages have never been a strong point of Hungarian education. According to a survey (Eurostat, 2019) of self-reported 
foreign language skills that was carried out in the 28 European Union member states in 2016, Hungary ranked third (57.6\%), after the United Kingdom (65.4\%) and Romania (64.2\%), on the list showing the number of working-age adults who claimed they did not know any foreign language. At least four out of every ten Hungarian adults of working-age reported that they knew at least one foreign language, whereas in Sweden, Latvia, Denmark or Luxembourg the ratio was nine out of ten. As for the level of command of the best-known foreign language, in Hungary almost half of the working-age adults (46.2\%) who knew at least one foreign language reported that they knew their best-known foreign language only at a basic level; $26.4 \%$ declared they were good, and not more than $25 \%$ believed to be proficient at their best-known foreign language (Eurostat, 2019). Research findings (Lugossy, 2009; Nikolov, 2003, 2008; Nikolov \& Józsa, 2006) demonstrated that the inadequacies of foreign language education in Hungarian primary schools were partly to blame for these discouraging figures. Instead of communicative language teaching, the principles of the behaviourist tradition, such as frontal class work, teaching and practising grammatical rules, rote learning of words and little focus on oral skills, have been typical of the foreign language classroom in Hungary.

\section{THE ROLE-PLAY ACTIVITY}

\subsection{Participants}

The participants were made up of a convenience sample of seven IMUTAs and four groups of Hungarian medical students who were learning EMP within the framework of two different elective courses held by the authors at four different times during the semester in which the study was carried out. One of the courses aims to prepare students for the B2 speaking subtest of PROFEX, which is an accredited, bilingual, EMP language test developed by our department. The objective of the second course is to improve medical students' oral skills. In both cases, medical students learn to communicate in English via scenarios they will be likely to encounter at work, for example, patient handoffs, medical history taking or giving presentations. These courses constitute weekly classes of 90-minutes during the semester.

Two groups of six and two groups of eight Hungarian medical students took part. Out of a total of 28 Hungarian students, 16 were in their third year, ten in their fourth and two in their fifth year. Within the framework of EMP courses offered by our department, they had been learning English on and off since they had started medical school. A total of 12 students had already passed the B2 PROFEX exam while 16 were programmed to sit the exam at the end of the semester in which the study was conducted. 
The seven IMUTAs were all international students enrolled in the Englishmedium programme of the medical school. They had been acting as IMUTAs to the authors for several years. One of the participating IMUTAs was Mathew (all names are pseudo names), who was a 21-year-old second-year American student at the time of the study. Teleola was a 23-year-old third-year medical student from Nigeria. Carla came from Mexico and was 22 years old and in her second year at the university. Priscilla was a 22-year-old second-year Brazilian girl. Ole, 22, came from Norway and was in his second year. Samira (24) and Mohammed (25) from Jordan were the most senior students, and were in their fourth year. Teleola and Carla, whose father was American, had attended English-medium primary and secondary schools, whereas Priscilla, Ole, Samira and Mohammed had attended high school where the language of instruction was English. All of them had been required to pass an in-house English language written test corresponding to B2 level (CEFR) before they gained admission to the English-medium program of the Medical School. In addition, their oral English language skills were assessed during the oral entrance exam, which was administered in English.

\subsection{Description of the role-play activities}

In EMP classes where the focus is on oral skills the Hungarian students are regularly engaged in role-play activities. During the last six classes of the courses included in the study, the participants were asked to role-play doctor-patient dialogues with the IMUTAs. By this time, the Hungarian and the international students became acquainted, since the IMUTAs had participated in previous classes during the semester. The Hungarian students played the role of the doctor, and the IMUTAs acted as patients. Each pair of students played the same role-play simultaneously. The scenarios were based on real cases, which were selected from a pool of medical cases our department had collected with the help of clinical doctors working at the affiliated hospitals of UPMS. The cases were selected so that the students had some medical knowledge of the given diseases (e.g. pneumonia, gallstone). All participants were assured beforehand that the aim of these activities was to improve their speaking skills in English and not to test their medical knowledge.

Two kinds of role-plays were utilised. In role-play 1, the Hungarian students' task was to take a patient's medical history using the prompts written on the card they were given initially (for an example see Appendix 1). During the conversation, they were to take notes, on the basis of which they had to summarise the case to the IMUTAs who played the role of the patient. The IMUTAs were also given a card with detailed information on their medical history, which they needed in order to answer the questions (for an example see Appendix 2). In role-play 2, similarly to the previous case, the Hungarian students played the role of the doctor, and the IMUTAs were the patients. In addition to taking the medical history, the Hungarian 
students were to establish the patient's diagnosis. The Hungarian students were initially provided with four plausible options from which they would choose the correct diagnosis at the end of the role-play, based on the information they had managed to collect (for an example see Appendix 3). These options helped the Hungarian students to decide what questions they needed to ask to make the diagnosis. As in role-play 1, the IMUTAs were given the details of their medical history in the form of a role-play card (for an example see Appendix 4). Before the role-play, the participants were given five minutes to prepare. Though the patient role-play card contained detailed information on the given patient's medical history, the IMUTAs were asked to try to improvise if the doctors, i.e. Hungarian students, inquired about something that was not mentioned on their role-play card.

After each role-play, a group discussion was initiated to allow for the teacher to give general feedback, and for the students to discuss any issues that had come up during the activity. While acting as a facilitator during the role-play activities, the teacher monitored the students and helped with any problems that arose. In most of the cases, the Hungarian students needed assistance in explaining something to the IMUTAs. In addition, some of the IMUTAs required reassurance that they could freely improvise if the Hungarian students asked them a question the answer to which was not included in their role-play card.

Students who completed certain foundation EMP classes could sign up for the courses that were involved in our study. Therefore, the participating Hungarian students were already familiar with the vocabulary of medical history taking in English at the beginning of the semester. In addition, before the role-play activities, two classes had been dedicated to history taking in English to refresh students' knowledge.

\section{RESEARCH METHODOLOGY AND DATA COLLECTION}

Due to a lack of previous literature on the use of international peer tutors in roleplays in the EMP context, the authors adopted a qualitative exploratory approach, as recommended in the case of under-researched areas (Dörnyei, 2007: 39). This approach does not offer final and conclusive answers to the research questions, but explores the topic with varying levels of depth. It has been noted that "exploratory research is the initial research, which forms the basis of more conclusive research. It can even help in determining the research design, sampling methodology and data collection method" (Singh, 2007: 64). It has also been stated that "an exploratory study may not have as rigorous a methodology as it is used in conclusive studies, and sample sizes may be smaller" (Nargundkar, 2003: 41). It can also be "used for major decisions about the way we are going to conduct our next study" (Nargundkar, 2003: 41). Unlike in quantitative research, qualitative studies use fewer participants because the goal is not to generalise the findings to a larger population, but to shed light on underlying phenomena (Mackey \& Gass, 
2005: 163). As Dörnyei (2007: 36) formulated it, the significance of qualitative research in applied linguistics has been increasing, since "every aspect of language acquisition and use is determined or significantly shaped by social, cultural, and situational factors, and qualitative research is ideal for providing insights into such contextual conditions and influences".

The data was collected with semi-structured, focus group interviews conducted with each group of Hungarian students in Hungarian at the end of the semester in May 2019. The interview data was recorded by an audio-recorder, transferred into electronic scripts, and translated into English by the authors. The dataset was then analysed for themes and issues (Creswell, 2003: 190-195; Mackey \& Gass, 2005: 178-179). We closely examined the data to identify common themes - topics, ideas and patterns of meaning that came up repeatedly in the data (Mackey \& Gass, 2005: 178-179).

Quotations from the interviews (printed in italics in the text) have been extracted to provide an in-depth understanding of the participants' views and to support the findings.

During the interviews, the questions elicited the participants' impressions, views and opinion of the use of role-plays with IMUTAs in the classroom. The questions that formed the basis of the semi-structured interviews were the following:

1. How did you find role-playing with your international peers in class?

2. What did you enjoy about working with the international students in class?

3. What difficulties did you have while working with the international students during role-plays?

4. What do you think the differences are between role-playing with your Hungarian peers and the international students in class?

5. In terms of language learning, what language skills do you think you managed to improve more effectively while working with the international students as opposed to when role-playing with Hungarian students?

6. Do you agree or disagree that the role-play activities improved your:
a. vocabulary
b. grammar skills
c. listening skills
d. pronunciation
e. speaking skills? If so, how and why?

7. Did you take the role-play task more seriously when working with the international students? If so, why?

8. Were you more motivated, interactive or collaborative during the role-plays with the international students (as opposed to when working with other Hungarian students)? If so, why?

9. In what way did these classes have an impact on your confidence in your English language knowledge? 
10. Do you have international friends? / How often do you hang out with international students at the university?

11. In what way did these classes with the international students change your attitude towards other cultures and the international students at the university?

\section{RESULTS}

After analysing the interviews for themes and issues we could identify five recurring themes in the dataset: 1) language learning outcome; 2) negotiating meaning and paraphrasing during role-plays; 3) making mistakes in class; 4) motivation; and 5) intercultural awareness.

In terms of language learning outcome, during the interviews six Hungarian students mentioned that one of the advantages of the role-plays with the IMUTAs was that they had the opportunity to become familiar with various English accents.

It was really useful that Teleola [Nigerian student] had an accent. It was a challenge to understand him. But we managed. And at the exam we often get listening tasks where they have accents, so it was very good. (HS1)

Four students also added, as HS2 formulated it, that "in real life people don't speak perfect English either"; therefore they "had better get used to it". Another benefit many students highlighted was that they could learn new idioms and expressions, and seemed to recall them later more easily:

I learned a lot of words and expressions from them [IMUTAs]. And they explained these words to me in English, and, probably that's why I remember them better. (HS3)

Ten participants appreciated that the IMUTAs were acting like, as HS1 formulated it, a "walking dictionary" and helped them whenever they "got stuck in the middle of the English sentence" (HS4).

As has been described above, due to the dominance of grammar, drills and translation, and little emphasis on fluency in the foreign language classroom, Hungarian students are often reluctant to speak English and participate in roleplays in class. The interviews revealed that the fear of making mistakes and losing face in front of the other students were the main reasons why most of the participants were unwilling to communicate in English in the classroom:

I have always been scared of saying something in English in class, because I have thought that my English has to be perfect and flawless. (HS5)

It became evident from the answers that during the role-plays the IMUTAs hardly ever corrected the Hungarian students' mistakes and appreciated all their 
contribution even if it was "not without mistakes" (HS4). They managed to create a supportive and friendly environment in which the Hungarian students did not feel intimidated when speaking English in front of the others:

Since these classes started, it has been much easier for me to start a conversion with the international students. I did not have the courage to talk to them before, because I was worried about how they would react if I made a mistake. Now I know that this doesn't matter, they don't mind it at all. (HS6)

Another participant (HS4) formulated similar ideas:

I felt that I did not have to speak perfect English and that it was more important that I actually said something in English. When we are working in pairs with Hungarian students we are concentrating on not making any mistakes, and therefore, we'd rather say only a few words or not speak at all in class.

In the interviews, ten participants also reported that when they could not express themselves in English during role-plays with other Hungarian students, instead of explaining or paraphrasing in English, they simply "switched to Hungarian". In contrast, while working with the IMUTAs, they had no other choice but to apply the strategies of paraphrasing and meaning negotiation to be able to complete the task:

Speaking is not my strong point, so I tend to give up soon and switch to Hungarian during pair works. But here I could not do it. I did not want to let them [IMUTAs] down, so I had to use English and paraphrase if I did not know the word in English. (HS7)

Although it meant hard work, eight Hungarian students still considered this aspect of working with the international students really beneficial:

It was a real advantage that they could not help us in Hungarian. So we had to solve the problem and paraphrase or explain to them the words we did not know how to say in English. That is what we will have to do in real life too. (HS8)

As for boosting motivation and class performance, the authors can testify that the IMUTAs were a big success. Even the shyest of students managed to make conversation in English, and, as many of them indicated in the interviews, build up their confidence throughout the semester:

After a few classes I became more confident and, therefore, participated more actively. (HS7)

Another student (HS9) added that: 
It was more interesting to speak to international students; I was really looking forward to these classes.

The interview results well demonstrated that Hungarian students' unwillingness to communicate in English in general and, especially with a Hungarian student, has a debilitating effect on learning and performing in class. Many participants mentioned that out of fear of making mistakes they would rather not say anything in English or switch to Hungarian whenever they could during classroom activities. Due to the IMUTAs' enthusiasm and supportive attitude, and the fact that they had no other choice but to use English, the Hungarian students "took the whole thing more seriously" and, as one of them (HS10) put it, still "managed to have fun and complete the task".

During the interviews, most of the Hungarian students reported that they did not really have foreign friends and did not socialise with the international students of the UPMS. As for the reasons, six of them expressed ideas similar to the following response:

I have always had the impression that they [the international students] are a bit cocky and not very inclusive. (HS9)

Others indicated that during these EMP classes they were pleasantly surprised by how "friendly" (HS8, HS4, HS5), "sociable" (HS10, HS11, HS15) and "supportive" (HS9, HS13, HS15) the international IMUTAs were. The interviews also revealed that in class, after completing the role-plays, the Hungarian and the international students often continued talking about topics they were interested in, such as each other's country or difficulties at the university:

When we were role-playing with Teleola or Carla, after we finished the role-play we often continued talking, usually about their countries or Hungary. (HS11)

During these discussions, many realised that their international peers were not that different after all:

It was interesting to see that they [the international students] have the same difficulties and problems that we would have if we went to study abroad, and they struggle with the same subjects as we do at the university. (HS12)

Role-playing with international students seemed to raise the intercultural awareness in some Hungarian students. Four of them mentioned that before this class they had not really distinguished the international students:

I did not differentiate between the cultures before. They were the international students when I met them at the university. Now, I can see that there are differences between them. (HS13) 
Except for three students who already had "foreign friends", all of the participants welcomed the idea of socialising more with the international students in the future. However, seven Hungarian students voiced their concern that "the English, German and Hungarian programmes of the university are completely separated", therefore, they had no common platform where they could regularly meet:

They are very easy-going and friendly. The problem is that we do not meet them; we are separated at the university. (HS13)

Six Hungarian students also reported that since they all went to the same university "it was much easier to find common ground" with IMUTAs and, in addition, the international students were also familiar with the context of medical history taking, so they could easily play along.

It was a huge help that they [IMUTAs] were also medical students and more or less familiar with medical history taking. They knew what I was trying to ask. (HS13)

\section{DISCUSSION}

The interviews demonstrated that the Hungarian medical students highly enjoyed the role-play activities with the IMUTAs and found them beneficial. They welcomed the opportunity to hear and get used to different accents, which is especially relevant in our globalised world where English has become a lingua franca. They reported being able to learn new vocabulary more easily and more effectively, which might result from the fact that these new words were heavily embedded in the context (Nunan, 1995), explained in English by peers and, immediately following that, used on the spot. By ignoring mistakes and creating a safe and supportive environment, the IMUTAs helped the Hungarian students overcome their anxiety caused by fear of making mistakes and embarrassing themselves in front of their peers. As a result, the Hungarian students reported to have become much more confident and willing to participate, i.e. communicate in English. The fact that they had no other choice since English was the only lingua franca might have been a gentle compelling force initially. However, as the time went by, they started to enjoy these role-plays and even "looked forward to these classes".

Negotiating meaning and paraphrasing are essential strategies not only in foreign language learning, but also in doctor-patient communication. In English as a foreign language context, students apply these strategies to avoid communication breakdowns. In a medical context, physicians often paraphrase or negotiate meaning to make sure that patients do not misunderstand them or vice versa, and to show patients that they are listening. Unlike when role-playing with other 
Hungarian peers and switching to Hungarian whenever a problem arises, while working with the IMUTAs, the Hungarian students could not avoid paraphrasing or explaining the words and expressions they could not express at first in English, which they themselves also found "useful".

Over the years, based on their own experience and before- and after-class discussions with the students, the authors have concluded that the majority of the international and Hungarian students do not mix at the university. The interviews confirmed this observation and shed some light on the reasons. Before these EMP classes, most of the Hungarian students had had the impression that the international students looked down on them and had no interest in getting to know them. However, while working with them in class, they discovered that, firstly, the "foreign" students were not all "the same", but from different cultures and countries. They also realised that their international peers were "not cocky at all", but "friendly" and "helpful", and had to face similar difficulties at the university. Many of them stated that they would like to make friends with the "foreign students" in the future. The Hungarian students also added that it was unfortunate that they only had very limited opportunities to socialise with them, since the students in the Hungarian, the English and the German programmes were completely separated at UPMS.

\section{CONCLUSION}

The present study was conducted to elicit Hungarian medical students' views and perceptions on utilising peer tutors, IMUTAs, in doctor-patient role-plays in EMP classes. The participants included four groups of Hungarian medical students and seven IMUTAs, who were either native speakers or had a good command of English and came from seven different countries. Within the framework of two language courses aiming to improve speaking and medical history taking skills in English, the participants were asked to role-play doctor-patient dialogues. By inviting international peer tutors into the classroom, the authors aimed to increase Hungarian students' willingness to communicate in English in class and improve motivation, engagement and performance. In addition, the authors intended to enhance the participants' intercultural competence by providing them a platform where they could work together and share experiences. A qualitative, exploratory approach was adopted during the research. The data was collected with semistructured, focus group interviews with the Hungarian students.

The answers the Hungarian students gave during the interviews showed that in EMP classes during oral activities PAL can decrease foreign language anxiety and increase students' willingness to communicate in English, and, consequently, may assist in improving their oral skills. The fact that the lingua franca in the class was the target language also seemed to help and prevented the EMP students from switching to their first language. On the spot building of vocabulary of medical history taking was also reported more beneficial and effective with peer tutors 
who were native speakers or had a good command of the English language. The Hungarian students' answers also revealed that in the EMP classroom role-playing and learning with students from other countries could assist in removing the invisible wall between students coming from different cultures, which is the first step in the development of intercultural competence, so essential in the medical profession.

Due to the small number of participants, the results of this study cannot be generalised; however, this was not our aim either. A qualitative, exploratory approach was adopted to gain an understanding of the Hungarian medical students' impressions and views on role-playing with international peer tutors in EMP classes. The study provided insights into the issues and helped to develop ideas and hypotheses for further conclusive research. As a second step, we are going to interview the participating IMUTAs to be able to supplement the results with their perspectives. In addition, we are planning to conduct further studies to measure if students' willingness to communicate (MacIntyre, Clement, Dörnyei, \& Noels, 2001) in EMP classes can be increased with the help of international peer tutors.

[Paper submitted 3 Jan 2020]

[Revised version received 6 Mar 2020]

[Revised version accepted for publication 14 Dec 2020]

\section{References}

Al-Senaidi, S. A. (2009). Using role-play to promote oral fluency. In S. Borg (Ed.), Understanding English language teaching and learning in Oman (pp. 66-72). Retrieved from http://www.moe.gov.om/Portal/sitebuilder/Sites/EPS/Arabic/IPS/Importa/tesol/ 3/Using\%20role\%20play\%20to\%20promote\%20oral\%20fluency.pdf

Betancourt, J. R., \& Green, A. R. (2010). Commentary: Linking cultural competence training to improved health outcomes: Perspectives from the field. Academic Medicine, 85(4), 583-585. https://doi.org/10.1097/acm.0b013e3181d2b2f3

Bowman-Perrott, L., deMarín, S., Lakshmi, M., \& Etchells, M. (2016). Assessing the academic, social, and language production outcomes of English language learners engaged in peer tutoring: A systematic review. Education and Treatment of Children, 39(3), 359-388. https://doi.org/10.1353/etc.2016.0016

Cate, O. T., \& Durning, S. (2007). Dimensions and psychology of peer teaching in medical education. Medical Teacher, 29(6), 546-552. https://doi.org/10.1080/01421590701583816

Cohen, L., Chavez, V., \& Chehimi, S. (2010). Prevention is primary: Strategies for community wellbeing (2nd ed.). San Francisco: Josey Bass.

Cole, M. W. (2013). Rompiendo el Silencio: Meta-analysis of the effectiveness of peermediated learning at improving language outcomes for ELLs. Bilingual Research Journal, 36(2), 146-166. http://dx.doi.org/10.1080/15235882.2013.814609

Cole, M. W. (2014). Speaking to read: Meta-analysis of peer-mediated learning for English language learners.Journal of Literacy Research,46(3),358-382. https://doiorg/10.1177/1086296X14552179

Crandall, S. J., George, G., Marion G. S., \& Davis, S. (2003). Applying theory to the design of cultural competency training for medical students: A case study. Academic Medicine, 78(6), 588-594. https://doi.org/10.1097/00001888-200306000-00007 
Creswell, J. (2003). Research design: Qualitative, quantitative and mixed methods approaches (2nd ed.). Thousand Oaks, CA: SAGE Publications.

Daetwyler, C. J., Cohen, D. G., Gracely E., \& Novack, D. H. (2010). eLearning to enhance physician patient communication: A pilot test of 'doc.com' and 'WebEncounter' in teaching bad news delivery. Medical Teacher, 32(9), e381-e390. https://doi.org/10.3109/0142159x.2010.495759

Dandavino, M., Snell, L., \& Wiseman, J. (2007). Why medical students should learn how to teach. Medical Teacher, 29(6), 558-65. https://doi.org/10.1080/01421590701477449

Dorathy, A. A., \& Mahalakshmi, S. N. (2011). Second language acquisition through taskbased approach: Role-play in English language teaching. English for Specific Purposes World, 33(1), 1-7.

Dörnyei, Z. (2007). Research methods in applied linguistics: Quantitative, qualitative, and mixed methodologies. Oxford: Oxford University Press.

Duxbury, J., \& Ling, T. (2010). The effects of cooperative learning on foreign language anxiety: A comparative study of Taiwanese and American universities. International Journal of Instruction, 3(1), 4-18.

Eurostat (2019). Foreign language skills statistics. Retrieved from https://ec.europa.eu/eurostat/statisticsexplained/index.php/Foreign_language_skills_statistics

Fantini, A. E. (2006). Exploring and assessing intercultural competence. Retrieved from http://www.sit.edu/publications/docs/feil_research_report.pdf

Franklin-Landi, R. (2017). Identifying and responding to learner needs at the medical faculty: The use of audio-visual specialised fiction (FASP). In C. Sarré, \& S. Whyte (Eds.), New developments in ESP teaching and learning research (pp. 153-170). Voillans, France: Research-publishing.net. https://doi.org/10.14705/rpnet.2017.cssw2017.750

Gass, S., \& Mackey, A. (2006). Input, interaction, and output: An overview. AILA Review, 19(1), 3-17.

Goode, T. D., Haywood, S. H., Wells, N., \& Rhee, K. (2009). Family-centered, culturally, and linguistically competent care: Essential components of the medical home. Pediatric Annals, 38(9), 505-512. https://doi.org/10.3928/00904481-20090820-04

Hamilton, J. (2009). Intercultural competence in medical education: Essential to acquire, difficult to assess. Medical Teacher, 31(9), 862-865. https://doi.org/10.1080/01421590802530906

Hild, G., Csongor, A., \& Németh, T. (in press). A longitudinal case study with four Norwegian students studying medicine in Hungary. Вопросы методики преподавания в вузе.

Hoekje, B. (2012). Teaching English for medical and health professionals. In C. Chapelle (Ed.), The encyclopedia of applied linguistics. Oxford: Blackwell. https://doi.org/10.1002/9781405198431.wbeal1154

Kleinman, A., \& Benson, P. (2006). Anthropology in the clinic: The problem of cultural competency and how to fix it. PLoS Med, 3(10), e294. https://doi.org/10.1371/journal.pmed.0030294

Kuśnierek, A. (2015). Developing students' speaking skills through role-play. World Scientific News, 1, 73-111. Retrieved from http://www.worldscientificnews.com/wpcontent/uploads/2012/11/WSN-1-2015-73-1112.pdf

Lie, D. A., Lee-Rey, E., Gomez, A., Bereknyei, S., \& Braddock, C. H. (2011). Does cultural competency training of health professionals improve patient outcomes? A systematic review and proposed algorithm for future research. Journal of General Internal Medicine, 14(3), 317-325. https://doi.org/10.1007/s11606-010-1529-0

Lockspeiser, T. M., O'Sullivan, P., Teherami, A., \& Muller, J. (2006). Understanding the experience of being taught by peers: The value of social and cognitive congruence. 
Advances in Health Sciences Education Theory and Practice, 13(3), 361-72. https://doi.org/10.1007/s10459-006-9049-8

Lugossy, R. (2009). "I will think about this": A case study with a lower-primary school teacher of English. In R. Lugossy, J. Horváth, \& M. Nikolov (Eds.), UPRT 2008: Empirical studies in English applied linguistics (pp. 59-69). Pécs: Lingua Franca Csoport.

MacIntyre, P. D., Clement, R., Dörnyei, Z., \& Noels, K. A. (2001). Conceptualizing willingness to communicate in a L2: A situational model of L2 confidence and affiliation. The Modern Language Journal, 82(4), 545-562. https://doi.org/10.1111/j.1540-4781.1998.tb05543.x

Mackey, A., \& Gass, S. M. (2005). Second language research: Methodology and design. Mahwah, NJ: Lawrence Erlbaum.

Marek, E., Schmél, D., Katz, Z., Faubl, N., Németh, T., Berényi, K., \& Szilárd, I. (2019). Gyógyítás és interkulturalitás [Treating and intercultural competence]. Egészségfejlesztés, 60(4), 6-21.

Mynard, J., \& Almarzouqi, I. (2006). Investigating peer tutoring. ELT Journal, 60(1), 13-22. https://doi.org/10.1093/elt/cci077

McWhinney, I. (1989). The need for a transformed clinical method. In M. Stewart, \& D. Roter (Eds.), Communicating with medical patients (pp. 25-40). Newbury Park, CA: Sage.

Nargundkar, R. (2003). Marketing research: Text and cases (2nd ed.). New Delhi: Tata McGraw-Hill Publishing Company Limited.

Németh, T., \& Tseligka, T. (2018). Initial results of a virtual exchange project between Greece and Hungary to improve medical students' intercultural and English language competence. ELTA Journal, 6(6), 77-88.

Nestel, D., \& Tierney, T. (2007). Role-play for medical students learning about communication: Guidelines for maximising benefits. BMC Medical Education, 7(1). https://doi.org/10.1186/1472-6920-7-3

Nikolov, M. (2003). Angolul és németül tanuló diákok nyelvtanulási attitűdje és motivációja [Language learning attitude and motivation of students learning English and German]. Iskolakultúra, 13(8), 61-73.

Nikolov, M. (2008). "Az általános iskola, az módszertan!" Alsó tagozatos angolórák empirikus vizsgálata ["The primary school is the real teaching methodology!": The empirical examination of lower-grade English as a foreign language classes]. Modern Nyelvoktatás, 10(1-2), 3-19.

Nikolov, M., \& Józsa, K. (2006). Relationships between language achievements in English and German and classroom-related variables. In M. Nikolov, \& J. Horváth (Eds.), UPRT 2006: Empirical studies in English applied linguistics (pp. 197-224). Pécs: Lingua Franca Csoport, PTE.

Nunan, D. (1995). Language teaching methodology: A textbook for teachers. Wiltshire: Prentice Hall International.

Olaussen, A., Reddy, P., Irvine, S., \& Williams, B. (2016). Peer-assisted learning: Time for nomenclature clarification. Medical Education Online, 21(1). https://doi.org/10.3402/meo.v21.30974

Pavel, E. (2014). Teaching English for medical purposes. Bulletin of the Transilvania University of Braşov. Series VII: Social Sciences \& Law, 7(56), 39-46.

Saha, S., \& Fernandez, A. (2007). Language barriers in health care. Journal of General Internal Medicine, 22(2), 281-282. https://doi.org/10.1007/s11606-007-0373-3

Sato, R. (2001). Role-play: Effective role-play for Japanese high school students. Retrieved from https://files.eric.ed.gov/fulltext/ED454709.pdf 
Schouten, B. C., \& Meeuwesen, L. (2006). Cultural differences in medical communication: A review of the literature. Patient Education and Counseling, 64(1-3), 21-34. https://doi.org/10.1016/j.pec.2005.11.014

Shapiro, S., \& Leopold, L. (2012). A critical role for role-playing pedagogy. TESL Canada Journal, 29(2), 120-130. https://doi.org/10.18806/tesl.v29i2.1104

Singh, K. (2007). Quantitative social research methods. New Delhi: SAGE Publications. https://dx.doi.org/10.4135/9789351507741

Staley, K., Allen, C., \& Hamp, A. (2020). Case studies in ESP course development: Medical English for Turkmen and Mexican medical specialists. English Teaching Forum, 58(1), 2-9.

Stigmar, M. (2016). Peer-to-peer teaching in higher education: A critical literature review. Mentoring \& Tutoring: Partnership in Learning, 24(2), 124-136. https://doi.org/10.1080/13611267.2016.1178963

Stütz, A., Green, W., McAllister, L., \& Eley, D. (2015). Preparing medical graduates for an interconnected world: Current practices and future possibilities for internationalizing the medical curriculum in different contexts. Journal of Studies in International Education, 19(1), 28-45. https://doi.org/10.1177\%2F1028315314536991

Topping, K. J., \& Ehly, S. W. (1998). Peer-assisted learning. Mahwah, NJ: Lawrence Erlbaum Associates.

Vygotsky, L. S. (1987). Thinking and speech. In R. W. Rieber, \& A. S. Carton (Eds.), The collected works of L. S. Vygotsky, Vol. 1: Problems of general psychology (pp. 39-285). New York: Plenum Press.

Zhang, Y. (2010). Cooperative language learning and foreign language learning and teaching. Journal of Language Teaching and Research, 1(1), 81-83. https://doi.org/10.4304/JLTR.1.1.81-83

GABRIELLA HILD, PhD is an assistant professor at the Department of Languages for Biomedical Purposes and Communication, Medical School, University of Pécs, Hungary. She teaches English for medical purposes to undergraduates and postgraduates and Hungarian for medical purposes to foreign undergraduates. She received her Ph.D. degree in 2015. She is also an OET (Occupational English Test) preliminary provider, and an item writer for Cambridge Assessment English. Her research interests include language testing, teaching English and Hungarian for medical purposes, and the study abroad experience.

TIMEA NÉMETH, PhD is an assistant professor at the Department of Languages for Specific Purposes at the Medical School of the University of Pécs, Hungary. She teaches English and Hungarian for Medical Purposes and intercultural competence for Hungarian and international undergraduate medical students. She also teaches modules at postgraduate level and in PhD programmes. She has international teaching experience and is actively involved in transnational projects focusing on multicultural education and the development of intercultural competence in healthcare settings. Her research interests include multiculturalism, intercultural communication and competence, intercultural language learning, study abroad programmes, internationalisation processes and the use of online educational tools in teaching. 
ALEXANDRA CSONGOR, PhD is an assistant professor at the Department of Languages for Biomedical Purposes and Communication, Medical School, University of Pécs, Hungary. Her professional interests relate to the study of English for medical and medical research objectives, the language use of written genres, the study of net linguistics and online genres. Currently, she is performing research throughout intercultural language learning, 21st century challenges in doctor-patient communication, and online educational tools predominantly used in higher education today. Recently, she joined the programme launched with the purpose of training simulated patients at the Medical School.

\section{Appendix 1 \\ Role-play 1 - Hungarian student card}

Your role: Internist working at the Outpatient clinic

Your patient: 59 year-old woman, weight loss, diabetes mellitus and abnormal liver function

Take the patient's medical history using the prompts below:

- Introduction

- Presenting complaints

- Nocturia

- Diabetes (onset, medication)

- Diet

- Blood sugar level

- Colour of the urine lately

- Vision

- General condition

- Weight

- Abdominal pain, character, radiation

- Chest pain

- Pain elsewhere

Identify risk factors

- Past medical history

- Operations

- Medication/allergy

- Smoking /alcohol

- Social history

- Travelling

- Family history

Inquire about the patient's concerns

\section{Appendix 2}

Role-play 1-IMUTA card

Your role: 59 year-old female patient

Location: Internal medicine outpatient clinic

- very thirsty recently, gets up to urinate 4-5 times during the night

diagnosed with type 2 diabetes 3 months ago, prescribed a drug but you cannot recall the name

doctor recommended a diet low in carbohydrates

- blood sugar level is still high, especially in the morning (13-14 mmol /L) 
- urine looks darker

- vision gets blurry

- feel generally unwell, weak, passive and no energy

- lost $11 \mathrm{~kg}$-s over the last 4 months despite eating normally

- episodes of upper right abdominal discomfort, sometimes a dull pain radiating to your back

- no chest pain, but palpitations (rapid heartbeat) when stressed

- some pain in the joints both in hands and ankles

- productive cough in the mornings, probably due to smoking

Past medical and surgical history:

- appendix removed at the age of 26

- high blood pressure for the last 15 years and cholesterol level is higher than normal

- medications: antihypertensive and statin medication

- allergic to Penicillin

\section{Risk factors:}

- smoking 10 cigarettes per day since the age of 30

- drinking about 2 glasses of wine at the weekends but it upsets the stomach

\section{Social and family history:}

- divorced, two sons

- working as a manager assistant

- family history of hypertension, but no diabetes in the family

You travelled to Thailand with friends in summer.

You are worried about losing so much weight and need more advice on a proper diet. You would also like to quit smoking.

\section{Appendix 3}

\section{Role-play 2 - Hungarian student card}

Diagnosis options:

- gallstone

- appendicitis

- kidney stone

. urinary tract infection

\section{Appendix 4}

Role-play 2 - IMUTA card

Your role: 42 year-old female primary school teacher

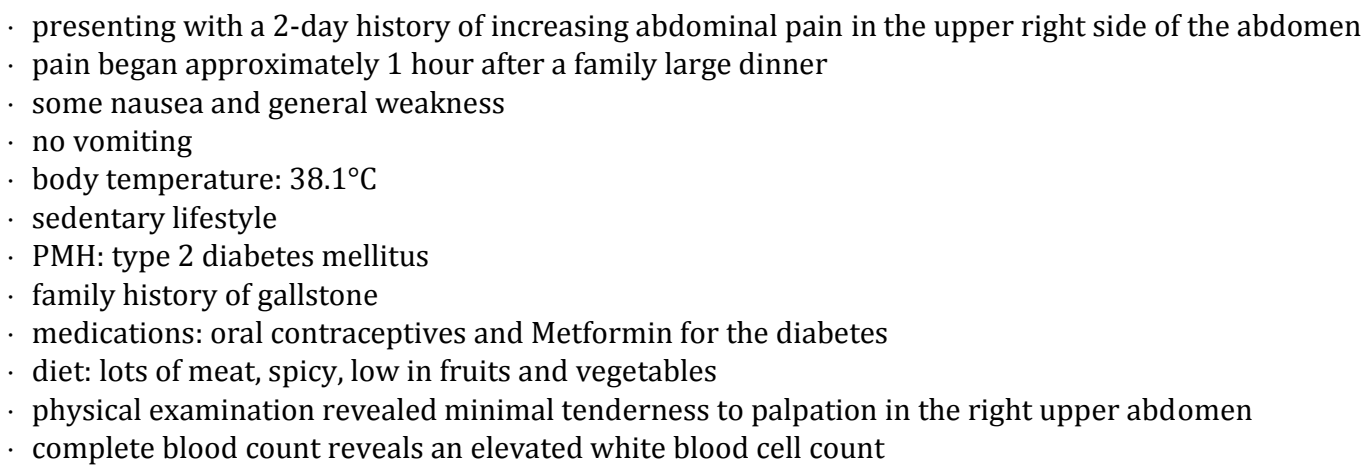

